\title{
Research Paper: Stereological Method for Assessing the Effect of Vitamin C Administration on the Reduction of Acrylamide-induced Neurotoxicity
}

\author{
Hengameh Dortaj ${ }^{1}$, Maryam Yadegari ${ }^{1}$, Mohammad Hosseini Sharif Abad ${ }^{1}$, Abolghasem Abbasi Sarcheshmeh ${ }^{1}$, Morteza Anvari $^{1 *}$
}

1. Department of Anatomy and Cell Biology, Faculty of Medicine, Shahid Sadoughi University of Medical Sciences and Health Services, Yazd, Iran

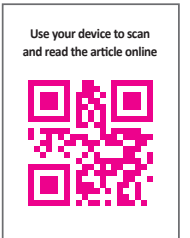

dtation: Dortaj, H., Yadegari, M., Hosseini Sharif Abad, M., Abbasi Sarcheshmeh, A., \& Anvari, M. (2018). Stereological Method for Assessing the Effect of Vitamin C Administration on the Reduction of Acrylamide-induced Neurotoxicity. Basic and Clinical Neuroscience, 9(1), 27-34. https://doi.org/10.29252/nirp.bcn.9.1.27

Article info:

Received: 28 December 2016 First Revision: 19 January 2017 Accepted: 30 April 2017
Key Words:

Acrylamide, Cerebellum, Vitamin C, Stereology, Neurotoxicity

\begin{abstract}
A B S T RA C T
Introduction: Acrylamide (ACR) consumption is increasing all over the world. There are some evidence on the literature about its neurotoxic effect on mature animals, but the effects of ACR on postnatal development have been less studied. The purpose of this study was to evaluate the effects of ACR on development of cortical layer, white matter, and number of Purkinje cells of the cerebellum in rat newborns.

Methods: This study was carried out on 20 female Wistar rats (average weight: 180 g, aged: two months). The rats were divided into four groups. Pregnant rats were orally fed with ACR $10 \mathrm{mg} / \mathrm{kg}$ and vitamin C $200 \mathrm{mg} / \mathrm{kg}$. In this study, 6 infants of each group (weighting 32-35 g) were randomly selected at day 21 after birth and placed under deep anesthesia and transcardial perfusion. Their cerebellums were fixed and histopathological changes were evaluated with Hematoxylin and Eosin (H\&E) staining and cresyl violet method. The volume of cerebellar cortical layers and number of Purkinje cells were investigated by Cavalieri's principle and physical dissector methods. The obtained data were analyzed by 1-way ANOVA and LSD test using SPSS. $\mathrm{P}<0.05$ considered as statistically significant.

Results: The results showed that newborns of ACR-treated female rats have decreased cerebellar weight $(\mathrm{P} \leq 0.05)$ and lower than average number of Purkinje cells $(\mathrm{P} \leq 0.001)$. ACR also decreased the volume of granular and molecular layer and increased the volume of white matter. While the results showed decreased in white matter volume in vitamin $\mathrm{C}$ group $(\mathrm{P} \leq 0.001)$.
\end{abstract}

Conclusion: ACR induces structural changes in the development of the cerebellar cortical layers in rat newborns, but these changes may be prevented by vitamin $\mathrm{C}$ as an antioxidant.

\section{Introduction

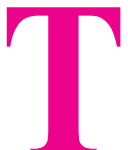 \\ he cerebellum is an ideal system to study pattern formation in the Central Nervous System (CNS) because of its simple cyto-}

architecture and regular organization of neural circuitry and folds (Trenkner, 1977). Because of the active development, neonatal life is a very sensitive period that could be easily affected by endogenous or exogenous factors. Acrylamide (ACR), $\mathrm{CH}_{2}=\mathrm{CH}-\mathrm{CONH}_{2}$, is a small water-

* Corresponding Author:

Morteza Anvari, PhD

Address: Department of Anatomy and Cell Biology, Faculty of Medicine, Shahid Sadoughi University of Medical Sciences and Health Services, Yazd, Iran Tel:+98 (913) 2160849

E-mail: moanvari@yahoo.com 
soluble vinyl monomer and hydrophilic molecule with so many chemical and industrial applications (Friedman, 2003). ACR polymer is used extensively in laboratories for gel chromatography and also in modern chemical technology, like filtration in water treatment or processing industries like paper mills (Singhal et al., 2008).

ACR is present in foods such as fried potato, cookies, and crackers that are prepared at very high temperature as a result of Maillard reaction between sugar and amino acids (e.g. asparagine) (Ayvaz, 2014). ACR has been classified as a probable carcinogen and is a well-documented neurotoxic in both humans and animals (Tilson $\&$ Cabe, 1978). Subchronic, low-level exposure of humans to ACR produces neurotoxi-city characterized by ataxia and skeletal muscle weakness of the feet (Shuming, Jilin \& Xichun, 2009).

Previous morphological studies suggest that both humans and experimental neurotoxicity were mediated by cerebellar Purkinje cell injury through degeneration of distal axon in the peripheral and central nervous system (Lehning, Balaban, Ross \& LoPachin, 2003). Purkinje cells have an inimitable persistence and exhibit unparalleled regenerative capabilities within the central nervous system. Their response to cell injury is unique among most neurons and can show degenerative, compensatory, and regenerative mechanisms (Lehning et al., 2003).

Axonal remodeling of Purkinje cells clearly increases in the disease. A disease-related increase in the frequency of Purkinje cell fusion and heterokaryon formation in ataxia cases have been reported (Lehning et al., 2003).

Vitamin C is important as an antioxidant in cellular function (Volterra, Trotti, Tromba, Floridi, \& Racagni, 1994). This antioxidant plays a pivotal role in neutralizing free radicals induced by oxidative recompense to lipids and lipoproteins in various cellular compartments and tissues (Volterra et al., 1994). CNS neurons contain some of the highest vitamin $\mathrm{C}$ concentration in tissues (Martin, Janigian, Shukitt-Hale, Prior, \& Joseph, 1999). Vitamin C is capable of crossing the blood-brain barrier and removing free radicals from both inside and outside the cells (Agus et al., 1997). Quantitative morphology of CNS has been recently undergone major development (Jacobson, 2013). Stereology meth-ods have been successfully applied to neuromorphological research (Schmitz \& Hof, 2005). The data on the effect of ACR on the postnatal development of cerebellum is rare (Kopańska, Lukáč, Kapusta, \& Formicki, 2015). So the aim of this study was to investigate the histopathological and stereological assessment for estimating the effect of vitamin $\mathrm{C}$ administration on the reduction of ACR induced neurotoxicity.

\section{Methods}

Chemical: ACR (99\% pure) and formaldehyde solution was purchased from Sigma chemical company. Vitamin C was purchased from Hakim Pharmaceutical Company, Iran.

\subsection{Experimental procedures}

The Ethics Committee of Shahid Sadoughi University of Medical Sciences approved all study procedures. In the present study, 20 young female Wistar rats were used and marked. They were housed 5 per cage and fed standard rodent pellet diet. Drinking water and rodent laboratory food were available ad libitum. The animal room was kept at $20^{\circ} \mathrm{C}-25^{\circ} \mathrm{C}$ and $50 \%$ humidity under $12: 12 \mathrm{~h}$ light-dark cycle.

Female rats were mated with males $(2: 1)$ in each cage. In the next morning, a positive sign of mating was confirmed by sperm-positive vaginal smears and the presence of copulatory plugs. The presence of sperm in the vaginal smear was determined at Day zero (D0) of gestation. The pregnant mothers were randomly labeled into 4 groups. Group A consisted of pregnant rats which were given distilled water (control group). Group B included pregnant rats which were given ACR from day 7 of gestation (D7). Group $\mathrm{C}$ were pregnant rats which received vitamin $\mathrm{C}$ from D7 of gestation. Finally, group D comprised pregnant rats which were given ACR+vitamin C from D7 of gestation. ACR was dissolved in distilled water and administered orally to pregnant rats at a dose of $10 \mathrm{mg} / \mathrm{kg}$ / day and vitamin C 200mg/kg/day (Raju et al., 2013).

\subsection{Animal perfusion}

To avoid physical injury, rats' cerebellums were fixed by perfusion before exposing them out of the skulls. Newborns were undergone transcardial perfusion 21 days after birth. The perfusion solution was $4 \%$ formaldehyde in $0.1 \mathrm{M}$ phosphate buffered saline. First, the animals were deeply anesthetized with diethyl ether. Then they were placed in supine position. The thoracic cavity was opened by parasagittal skin incision. To perform perfusion, right atrium was opened to permit the blood and the fixative leave the body. Next, the rats were perfused with perfusion solution (14\% of total body weight) for 10-15 minutes until the fluid that comes out of the rat became clear. After perfusion, the skull was cut and the entire cerebellum was weighed (Villringer, Them, Lindauer, Einhaupl, \& Dirnagl, 1994). 


\subsection{Histology assessment}

For histological analysis of newborn cerebellum, the whole cerebellum was dissected and inserted into Bovine fixative at room temperature overnight for 2 days and then transferred to $70 \%$ ethanol. For light microscopic study, after fixation the samples were dehydrated by alcohol, cleared in xylene, and then embedded in paraffin wax. Sections ( $5 \mu \mathrm{m}$ thick) were stained with Hematoxylin and Eosin (H\&E) and with cresyl violet method to identify neurons. Stereological analysis and the grids were used to determine the volume of the cerebellum layers and number of Purkinje cells (Tunc et al., 2006).

\subsection{Stereology assessment}

\subsubsection{Cortex volume}

The volume of the cerebellum was estimated by using the Cavalieri's principle method (Heidari \& Mahmoudzadeh-Sagheb, 2012). Cavalieri's method allows for the estimation of total volume from area on a systemic-random sampling of sections through the objects. The grid points were randomly superimposed over each section under a dissecting microscope and the points falling on the cerebellum were counted. On the average, 180-200 hits per cerebellum was counted. Volume of the cerebellum was determined by applying the following formula:

$$
V=\Sigma P \times t \times d \times a / p
$$

, where $t$ is the fixed thickness of the slabs of the cerebellum $(5 \mu \mathrm{m}), \mathrm{a} / \mathrm{p}$ is the area associated with each point of the grid, and $\Sigma \mathrm{P}$ refers to the total number of points that hit with the cerebellum cortex (Heidari \& Mahmoudzadeh-Sagheb, 2012). An average of $10 \mathrm{sec}-$ tions was counted per cerebellum. The magnification of cerebellum using a light microscope was $100 \mathrm{x}$ for embryonic cerebellums and 40x for newborns. At this magnification, the differentiation between cortex and white matter can be performed.

\subsection{Number of Purkinje cell}

\subsubsection{Numerical density of Purkinje neurons}

The numerical density of neurons was counted by the physical dissector method. The dissector consists of a pair of serial sections, a "look-up" section and a "reference" section, with fix distance "h." According to the dissector method, neurons to be counted are those that can determine in the reference section and not on the lookup section (West, 1999). In the present study, a randomly selected area of cerebellar cortex from the reference sec- tion was taken for staining process. An equivalent region of cerebellar cortex from the look-up section was also photographed. On the photographs, the transparent pointcounting grid was randomly thrown on the reference section and after that it was superimposed on the same region of look-up section. Then, neurons within the grid and those intercepted by the right vertical and top grid bars (ac-ceptance line) were counted but those intercepted by the left vertical and bottom bar (forbidden line) were not included in the count. Then, the numerical density in any region was calculated using the formula (Behnam-Rasouli, Nikravesh, Mahdavi-Shahri \& Tehranipour, 2000).

$$
N=\Sigma Q / a / f \cdot h \Sigma P
$$

, where $\mathrm{N}$ refers to numerical density, $\mathrm{Q}$ is the number of cells seen on the reference section not on the look-up section, $\mathrm{a} / \mathrm{f}$ is the area associated with each frame, $\mathrm{h}$ denotes the distance between sections, and $\mathrm{P}$ is the number of frames associated points hitting the tissue.

\subsubsection{Total number of Purkinje cells}

After estimation of the number of neurons per unit volume (numerical density) and volume of cerebellar cortex, the total number of Purkinje cells in cerebellum is estimated. The total number of neurons was calculated by the following mathematical equation (West, Slomianka \& Gundersen, 1991).

\section{$N n=N . V$}

, where $\mathrm{Nn}$ is the total number of neurons, $\mathrm{N}$ refers to numerical density of Purkinje neurons, and V is the volume of cerebellar cortex.

\subsection{Statistical analysis}

Statistical significance was determined by 1-way Analysis of Variance (ANOVA) to compare the normal vs. experimental groups. Post hoc test for this estimation was Least-Square Distance (LSD). Statistical anal-ysis was performed using SPSS (version 19). A probability of less than 0.05 was considered a significant difference between group means.

\section{Results}

Signs of ACR toxicity; weakness of hind-limb muscles and paralysis were observed in the newborns from ACRtreated rats (Figure 1). Comparative histological changes in 4 groups and light photomicrographs in H\&E staining of Purkinje cells in neonatal period by using grid and physical 


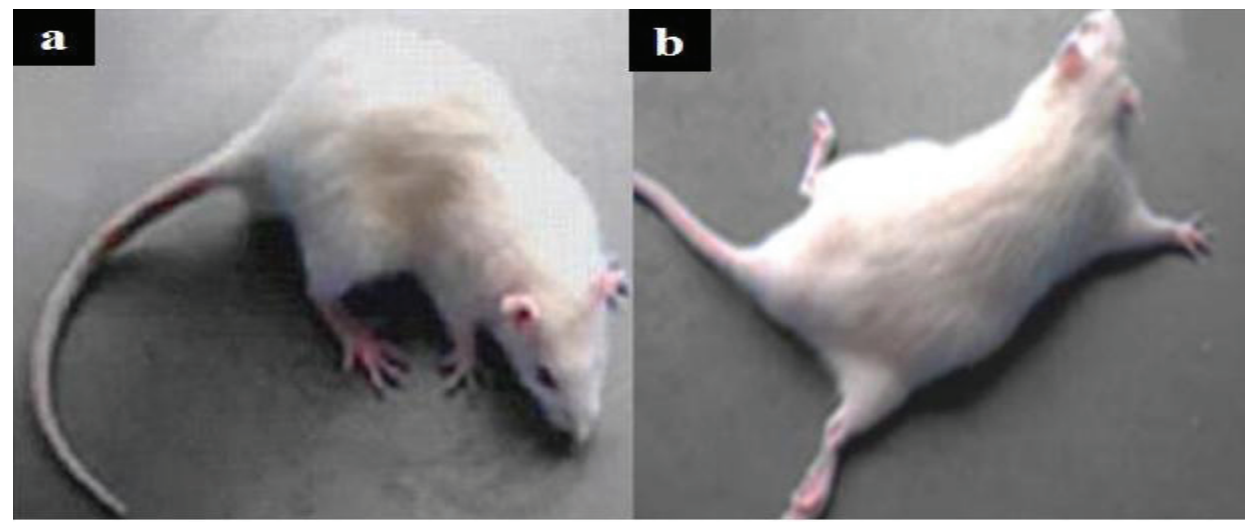

NEUR:SCIENCE

Figure 1. Signs of ACR anatomical changes

a: There were not any changes in hind-limbs of the control group; b: Weakness of hind-limb muscles and paralysis were observed in ACR-treated newborns after birth.

dissector are shown in Figure 7. Comparative histological and stereological changes in 4 groups using cresyl violet staining showed for estimating number of Purkinje cells (Figure 8) and volume of cerebellum (Figure 9).

\subsection{Volume of molecular layer in newborn}

Stereological investigation in the volume of molecular layer 21 days after birth, in ACR $(\mathrm{P}<0.001)$ and $\mathrm{ACR}+$ vitamin $\mathrm{C}$ groups $(\mathrm{P}=0.011)$ was significantly decreased compared with the control group, but was significantly increased $(\mathrm{P}<0.001)$ in the vitamin $\mathrm{C}$ group vs. control group (Figures 2, 9).

\subsection{Volume of granular layer in newborn}

Stereological investigation showed that the volume of granular layer at day 21 after birth, in ACR and $\mathrm{ACR}+$ vitamin $\mathrm{C}$ groups was significantly decreased

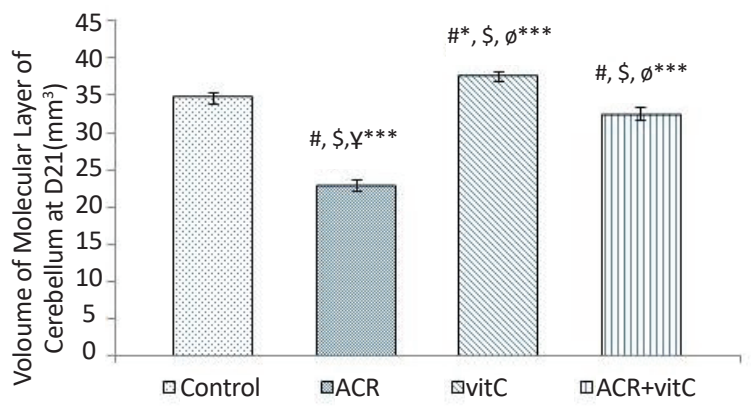

NEUR:SCIENCE

Figure 2. Volume of molecular layer in newborn rats $\left(\mathrm{mm}^{3}\right)$ \#: Estimating the comparison between the control and other groups; \$: Comparison between vitamin $\mathrm{C}$ group and the other groups; Ұ: Comparison between ACR+vitamin C group and other groups; $\Phi$ : Comparison between ACR and other groups; * $(\mathrm{P}<0.05)$; ** $\mathrm{P}<0.001$ compared with the control group $(\mathrm{P}<0.001)$, but this reduction in volume of granular layer in ACR group compared to ACR+vitamin $\mathrm{C}$ group was significant $(\mathrm{P}=0.005)$. Volume of the granular layer in vitamin $\mathrm{C}$ group vs. control group was significantly increased $(\mathrm{P}<0.001)$ (Figures 3 and 9).

\subsection{Volume of white matter in newborn}

Stereological investigation showed that volume of white matter 21 days after birth, in ACR and ACR+ vtamin $C$ groups was significantly increased compared with the control group $(\mathrm{P}<0.001)$. White matter volume in vitamin $\mathrm{C}$ group vs. control group was significantly decreased $(\mathrm{P}<0.001)$ (Figures 4 and 9$)$.

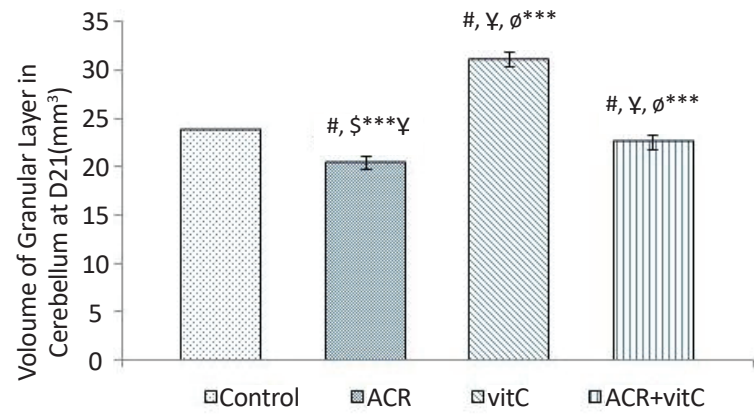

NEUR:SCIENCE

Figure 3. Volume of granular layer at D21 of newborn rats $\left(\mathrm{mm}^{3}\right)$

\#: Estimating the comparison between the control and other groups; \$: Comparison between vitamin $C$ group and other groups; Ұ: Comparison between $\mathrm{ACR}+$ vitamin $\mathrm{C}$ group with other groups; $\Phi$ : Comparison between ACR group with other groups; * $\mathrm{P}<0.05$; *** $\mathrm{P}<0.001$ 


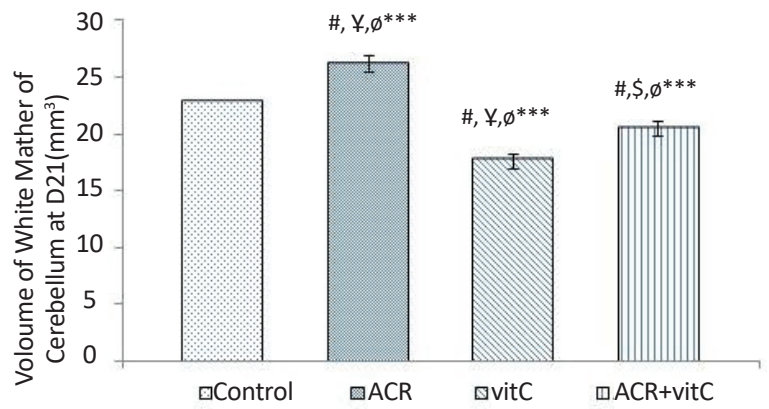

NEUR:SCIENCE

Figure 4. Volume of cerebellum white matter at D21 in $\mathrm{mm}^{3}$ \#: Estimating the comparison between the control group and other groups; $\$$ : Comparison between vitamin $C$ group and other groups; Ұ: Comparison between ACR+vitamin $C$ group and other groups; $\Phi$ : Comparison between ACR group with other groups. ${ }^{* *} \mathrm{P}<0.001$

\subsection{Whole volume of cerebellum}

Stereological investigation showed that the total volume of the cerebellum at day 21, in ACR and ACR+vitamin $\mathrm{C}$ groups was significantly decreased compared with the control group $(\mathrm{P}<0.001)$. While the total volume of the cerebellum in vitamin $\mathrm{C}$ group vs. control group was significantly increased $(\mathrm{P}<0.001)$ (Figures 5,9$)$.

\subsection{Number of Purkinje cell}

The results showed that ACR affected newborns and decreased the average number of Purkinje cells $(\mathrm{P} \leq 0.001)$ and vitamin $\mathrm{C}$ increased the average number of Purkinje cells $(\mathrm{P} \leq 0.001)$. In $\mathrm{ACR}+$ vitamin $\mathrm{C}$

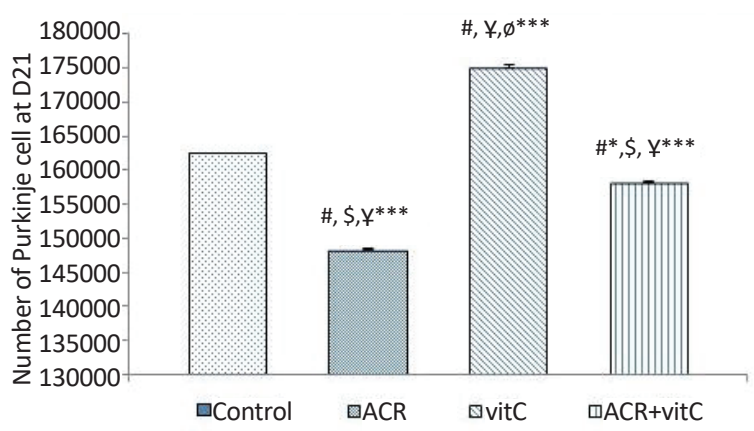

NEUR:SCIENCE

Figure 6. Number of Purkinje cell at D21

\#: Comparison between the control group and other groups; $\$$ : Comparison between vitamin $C$ group and other groups: ¥: Comparison between $\mathrm{ACR}+$ vitamin $\mathrm{C}$ group and other groups: $\Phi$ : Comparison between ACR with other groups; * $\mathrm{P}<0.05 ; * * * \mathrm{P}<0.001$

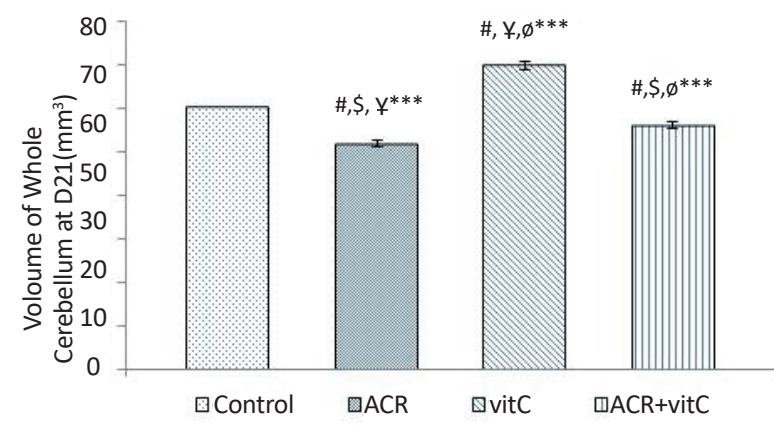

NEUR:SCIENCE

Figure 5. Volume of whole cerebellum at D21 $\left(\mathrm{mm}^{3}\right)$

\#: Comparison between the control group and other groups; $\$$ : Comparison between vitamin $C$ group and other groups; Ұ: Comparison between ACR+vitamin C group and other groups; $\Phi$ : Comparison between ACR group and other groups; *** $\mathrm{P}<0.001$

group, this reduction was significant compared to the control group $(\mathrm{P}=0.006)$ (Figures 6-8).

\section{Discussion}

In the present study, administration of ACR caused a significant decrease in molecular, volume of granular, whole cerebellum volume, and average number of Purkinje cells. It also increased volume of white matter cerebellum in newborn measured 21 days after birth. In this study, the stereological technique, $\mathrm{H} \& \mathrm{E}$ and cresyl violet were used to assess changes in the cerebellum. The information on the effects of tissue damage caused by eating fried starch-containing acrylamide during pregnancy on the development of fetus nervous system is scarce. Thus this study aimed to fill this information gap.

The previous studies demonstrated that ACR acts as a neurotoxic in both laboratory animals and humans (LoPachin, 2005). In the current study, the volume of cerebellar cortex was found to be shrunk in both ACR and $\mathrm{ACR}+$ vitamin $\mathrm{C}$ treated animals. Thus, it appears that exposure of animals to ACR might affect the cerebellum development. Impaired growth and development in embryonic period may be due to the toxic effects of ACR crossing through placenta during pregnancy (Duarte-Salles et al., 2012). Stereological analysis showed a decrease in the volume of molecular and granular layer of the cerebellum and in-crease in the volume of white matter in newborns in $\mathrm{ACR}$ and $\mathrm{ACR}+$ vitamin $\mathrm{C}$ groups.

Reduction in molecular and granular layer volume in these two groups may be the result of the process that damages nerves terminals in this region. Increase in the volume of white matter in $\mathrm{ACR}$ and $\mathrm{ACR}+$ vitamin $\mathrm{C}$ 


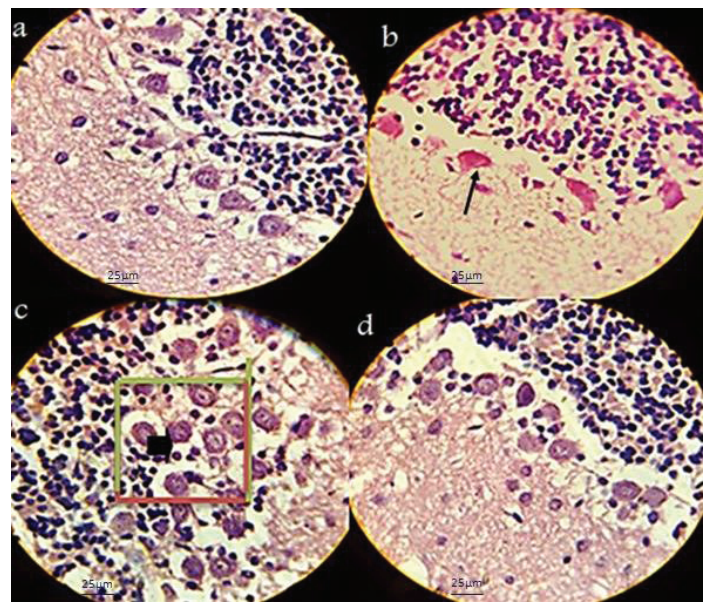

NEUR:SCIENCE

Figure 7. Light photomicrographs estimating the number of Purkinje cells in neonatal period by using grid and physical dissector H\&Ex1000

Forbidden and allowed sides to count red and green are separated. Decreasing in Purkinje cells in the ACR group (arrow) and increasing cells seen in the vitamin C group (arrow head). a: Control; b: ACR; c: Vitamin C; d: ACR+vitamin C; Scale bar: $25 \mu \mathrm{m}$

groups may be due to increase in myelin synthesis to compensate the reduction of gray matter (Gold, Griffin, \& Price, 1985). Development of nerve cells in laboratory animals and humans occur over a period of time before birth and continues in the cerebellum, even after birth. According to most studies, nerve cells are made
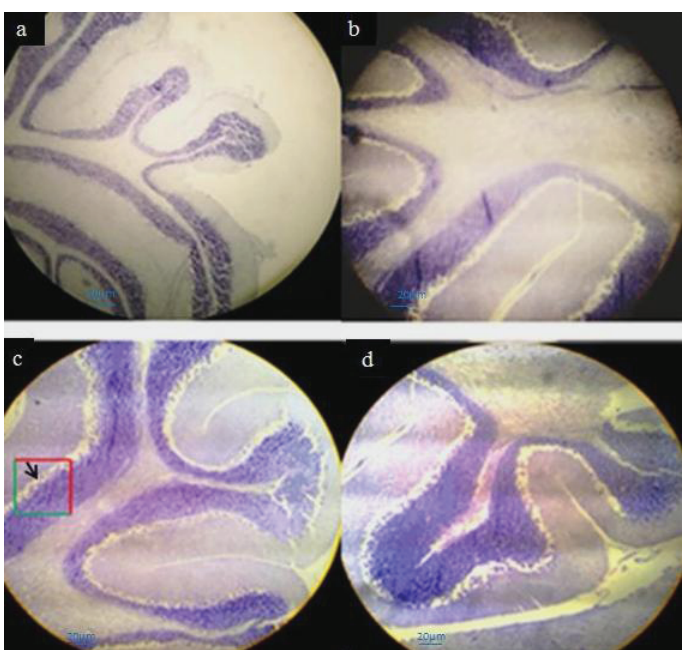

NEUR:SCIENCE

Figure 8. Light photomicrographs estimating the number of Purkinje cells in neonatal period by using grid and physical dissector cresyl violet staining $(\times 100)$

Forbidden and allowed sides to count red and green are separated. Decreasing in Purkinje cells in the group of ACR and the number of Purkinje cell was increased in the vitamin C group (arrow). a: Control; b: ACR; c: Vitamin C; d: ACR+vitamin C; Scale bar: $20 \mu \mathrm{m}$ in the mid-term pregnancy and then began to migrate to their final locations (Clendeninn, Petraitis \& Simon, 1976; Sidman \& Rakic, 1973). The results showed that administration of ACR to pregnant rats would result in a significant reduction in the average size of the cerebellum in new-borns compared to the control group. This result was in agreement with previous findings that showed the sensitivity of the brain cells in neonatal nutrition during pregnancy and lactation by ACR (Zeisel, 2004; El-Sayyad et al., 2011).

Research studies have shown that $10 \%$ to $15 \%$ of ACR in the diet of pregnant women are transmitted to the fetus through the placenta and more than $8.18 \mathrm{mg} / \mathrm{L}$ through the breast milk (El-Sayyad et al., 2011; Sörgel et al., 2002). Thus the concerns over the exposure of mothers to ACR in the food has been increased (Brantsæter et al., 2008). Evidence suggests that the binding proteins in the Central Nervous System (CNS) to produce the enzymes that compound with ACR play an important role in the neurotoxicity of ACR (Sakr, Badawy, El-Sayyad \& Afify, 2011). Barber and colleagues reported that ACR during prenatal period induces biochemical disorders, oxidative stress, and changes in the structure of the cerebellum (Barber \& LoPachin, 2004). This probably occurs due to increased Reactive Oxygen Species (ROS) levels in the tissues (Rydberg et al., 2003). Their result was in agreement with the results of the current
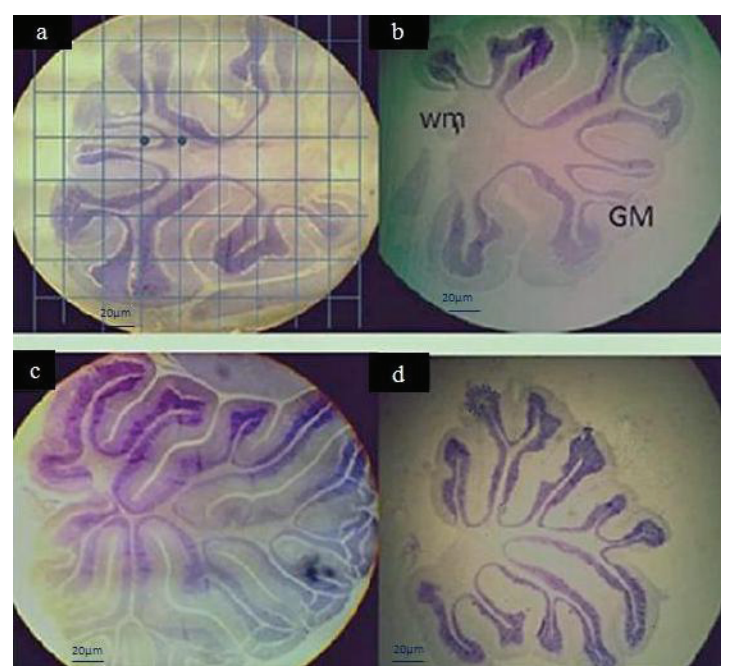

NEUR SCIENCE

Figure 9. Light photomicrographs estimating volume of Gray Matter (GM), White Matter (WM), and whole cerebellum in neonatal period by using grid and physical dissector cresyl violet staining $(\times 4)$

Cerebellar white matter volume increases in ACR group and gray matter increase in vitamin $C$ group comparing with the control group. a: Control; b: ACR; c: Vitamin C; d: ACR+vitamin C; Scale bar: $20 \mu \mathrm{m}$ 
study that ACR induces some changes in the structure of the cerebellum.

Antioxidants such as vitamin $\mathrm{C}$ act by binding with free radicals in tissues (Machlin \& Bendich, 1987; Fang, Yang \& Wu, 2002; Ou et al., 2010). The use of vitamin $\mathrm{C}$ in this study reduced the damaging effects of ACR. The key role of the cerebellum in balance and its formation during fetal life highlight the importance of research on the protection of children from embryonic period exposure to ACR. The idea that animal research, particularly those related to pharmaceuticals and environmental agents, may be a poor predictor of human experience is not new. Some limitations of animal model studies in hu-man research lies in planning, conducting, and critically evaluating studies utilizing animal models. Despite their limitations, animal models remain fundamental in improving our understanding of human toxicology. In conclusion, the present study showed that the neurological damage of the cerebellum under the effect of ACR can be minimized by vitamin $\mathrm{C}$; this may be due to its antioxidant and free radical scavenging activities.

\section{Acknowledgments}

This paper is derived from the MSc. thesis of Hengameh Dortaj and financially supported by Shahid Sadoughi University of Medical Sciences and Health Services, Yazd, Iran. We would like to thank the Department of Anatomy and Cell Biology for their official cooperation.

\section{Conflict of Interest}

The author declare no conflict of interest.

\section{References}

Agus, D. B., Gambhir, S. S., Pardridge, W. M., Spielholz, C., Baselga, J., Vera, J. C., et al. (1997). Vitamin C crosses the bloodbrain barrier in the oxidized form through the glucose transporters. Journal of Clinical Investigation, 100(11), 2842-48. doi: 10.1172/jci119832

Ayvaz, H. (2014). Rapid assessment of acrylamide and its precursors in potato tubers and snacks by infrared spectroscopy $[\mathrm{PhD}$ dissertation]. Columbus, Ohio: Ohio State University.

Barber, D. S., \& LoPachin, R. M. (2004). Proteomic analysis of acrylamide-protein adduct formation in rat brain synaptosomes. Toxicology and Applied Pharmacology, 201(2), 120-136. doi: 10.1016/j.taap.2004.05.008

Behnam-Rasouli, M., Nikravesh, M. R., Mahdavi-Shahri, N., \& Tehranipour, M. (2000). Post-operative time effects after sci- atic nerve crush on the number of alpha motoneurons, using a stereological counting method (Disector). Iranian Biomedical Journal, 4(1), 45-9.

Brantsæter, A. L., Haugen, M., Mul, A. de., Bjellaas, T., Becher, G., Klaveren, J. V., et al. (2008). Exploration of different methods to assess dietary acrylamide exposure in pregnant women participating in the Norwegian Mother and Child Cohort Study (MoBa). Food and Chemical Toxicology, 46(8), 2808-14. doi: 10.1016/j.fct.2008.05.020

Clendeninn, N. J., Petraitis, M., \& Simon, E. J. (1976). Ontological development of opiate receptors in rodent brain. Brain Research, 118(1), 157-60. doi: 10.1016/0006-8993(76)90852-0

Duarte-Salles, T., Von Stedingk, H., Granum, B., Gützkow, K. B. Rydberg, P., Törnqvist, M., et al. (2012). Dietary acrylamide intake during pregnancy and fetal growth-results from the Norwegian mother and child cohort study (MoBa). Environmental Health Perspectives, 121(3). doi: 10.1289/ehp.1205396

El-Sayyad, H. I., El-Gammal, H. L., Habak, L. A., Abdel-Galil, H. M., Fernando, A., Gaur, R. L., et al. (2011). Structural and ultrastructural evidence of neurotoxic effects of fried potato chips on rat postnatal development. Nutrition, 27(10), 1066-75. doi: 10.1016/j.nut.2011.06.008

Fang, Y. Z., Yang, S., \& Wu, G. (2002). Free radicals, antioxidants, and nutrition. Nutrition, 18(10), 872-79. doi: 10.1016/s08999007(02)00916-4.

Friedman, M. (2003). Chemistry, biochemistry, and safety of acrylamide. A Review. Journal of Agricultural and Food Chemistry, 51(16), 4504-26. doi: 10.1021/jf030204 .

Gold, B. G., Griffin, J. W., \& Price, D. (1985). Slow axonal transport in acrylamide neuropathy: different abnormalities produced by single-dose and continuous administration. Journal of Neuroscience, 5(7), 1755-68. PMID: 2410575

Heidari, Z., \& Mahmoudzadeh-Sagheb, H. (2012). Quantitative study of volumetric changes of cerebellum in male adult rat following lithium administration. International Journal of High Risk Behaviors and Addiction, 1(2), 66-70. doi: 10.5812/ ijhrba.4187

Jacobson, M. (2013). Developmental neurobiology. Berlin: Springer.

Kopańska, M., Lukáč, N., Kapusta, E., \& Formicki, G. (2015). Acrylamide influence on activity of acetylcholinesterase, thiol groups, and malondialdehyde content in the brain of swiss mice. Journal of Biochemi-cal and Molecular Toxicology, 362(11), 121-34

Lehning, E., Balaban, C., Ross, J., \& LoPachin, R. (2003). Acrylamide neuropathy. II. Spatiotemporal characteristics of nerve cell damage in brainstem and spinal cord. Neurotoxicology. 24(1),109-23. PMID: 12564387

LoPachin, R. M. (2005) Acrylamide neurotoxicity: neurological, morhological and molecular endpoints in animal models. In: M. Friedman, D. Mottram (Eds.), Chemistry and Safety of Acrylamide in Food. Advances in Experimental Medicine and Biology, Vol 561 (pp. 21-37). Berlin: Springer.

Machlin, L. J., \& Bendich, A. (1987). Free radical tissue damage: protective role of antioxidant nutrients. The FASEB Journal, 1(6), 441-45. doi: 10.1096/fasebj.1.6.3315807

Martin, A., Janigian, D., Shukitt-Hale, B., Prior, R. L., \& Joseph, J. A. (1999). Effect of vitamin $E$ intake on levels of vitamins $E$ and 
$\mathrm{C}$ in the central nervous system and peripheral tissues: implications for health recommendations. Brain Research, 845(1) 50-9. doi: 10.1016/s0006-8993(99)01923-x

Ou, S., Shi, J., Huang, C., Zhang, G., Teng, J., Jiang, Y., et al. (2010). Effect of antioxidants on elimination and formation of acrylamide in model reaction systems. Journal of Hazardous Materials, 182(1-3), 863-68. doi: 10.1016/j.jhazmat.2010.06.124

Raju, K. T., Venkataswamy, M., Subbaiah, K., Suman, B., Meenabai, M., \& Rao, K. (2013). Depletion of vitamin-C and glutathione by acrylamide causes damage to hippocampus region of brain in chick embryo. International Journal of Advances in Pharmaceutical Research, 4(3), 1471-9.

Rydberg, P., Eriksson, S., Tareke, E., Karlsson, P., Ehrenberg, L., \& Törnqvist, M. (2003). Investigations of factors that influence the acrylamide content of heated foodstuffs. Journal of A gricultural and Food Chemistry, 51(24), 7012-8. doi: 10.1021/jf034649+

Sakr, S. A., Badawy, G. M., El-Sayyad, H. I., \& Afify, H. S. (2011) Adverse effects of acrylamide on the developing retina of albino rats. Journal of Basic and Applied Scientific Research, 1(7), 706-12.

Schmitz, C., \& Hof, P. R. (2005). Design-based stereology in neuroscience. Neuroscience, 130(4), 813-31. doi: 10.1016/j.neuroscience.2004.08.050

Shuming, C., Jilin, F., \& Xichun, Z. (2009). The moderating role of dark soy sauce to acrylamide-induced oxidative stress and neurophysiological perturbations in rats. Toxicology Mechanisms and Methods, 19(6-7), 434-440. doi: $10.1080 / 15376510903136895$

Sidman, R. L., \& Rakic, P. (1973). Neuronal migration, with special reference to developing human brain: A review. Brain Research, 62(1), 1-35. doi: 10.1016/0006-8993(73)90617-3

Singhal, R. S., Kennedy, J. F., Gopalakrishnan, S. M., Kaczmarek, A., Knill, C. J., \& Akmar, P. F. (2008). Industrial production, processing, and utilization of sago palm-derived products. Carbohydrate Polymers, 72(1), 1-20. doi: 10.1016/j. carbpol.2007.07.043

Sörgel, F., Weissenbacher, R., Kinzig-Schippers, M., Hofmann, A., Illauer, M., Skott, A., et al. (2002). Acrylamide: Increased concentrations in homemade food and first evidence of its variable absorption from food, variable metabolism and placental and breast milk transfer in humans. Chemotherapy, 48(6), 267-74. doi: 10.1159/000069715

Tilson, H. A., \& Cabe, P. A. (1978). Strategy for the assessment of neurobehavioral consequences of environmental factors. Environmental Health Perspectives, 26, 287-299. doi: 10.1289/ ehp.7826287

Trenkner, E. (1977). Histogenesis of mouse cerebellum in microwell cultures. Cell reaggregation and migration, fiber and synapse formation. The Journal of Cell Biology, 75(3), 915-940. doi: $10.1083 /$ jcb.75.3.915

Tunç, A. T., Turgut, M., Aslan, H., Sahin, B., Yurtseven, M. E., \& Kaplan, S. (2006). Neonatal pinealectomy induces Purkinje cell loss in the cerebellum of the chick: A stereological study. Brain Research, 1067(1), 95-102. doi: 10.1016/j.brainres.2005.10.011

Volterra, A., Trotti, D., Tromba, C., Floridi, S., \& Racagni, G. (1994). Glutamate uptake inhibition by oxygen free radicals in rat cortical astrocytes. The Journal of Neuroscience, 14(5), 2924 32. PMID: 7910203
Villringer, A., Them, A., Lindauer, U., Einhaupl, K., \& Dirnagl, U. (1994). Capillary perfusion of the rat brain cortex. An in vivo confocal microscopy study. Circulation Research, 75(1), 55-62. doi: 10.1161/01.res.75.1.55

West, M. J., Slomianka, L., \& Gundersen, H. J. G. (1991). Unbiased stereological estimation of the total number of neurons in the subdivisions of the rat hippocampus using the optical fractionator. The Anatomical Record, 231(4), 482-497. doi: 10.1002/ ar.1092310411

West, M. J. (1999). Stereological methods for estimating the total number of neurons and synapses: issues of precision and bias. Trends in Neurosciences, 22(2), 51-61. doi: 10.1016/s01662236(98)01362-9

Zeisel, S. H. (2004). Nutritional importance of choline for brain development. Journal of the American College of Nutrition 23(sup6), 621S-626S. doi: 10.1080/07315724.2004.10719433 